\title{
The Suitability of the Health Belief Model as an Assessment Framework for Women With Breast III- Health
}

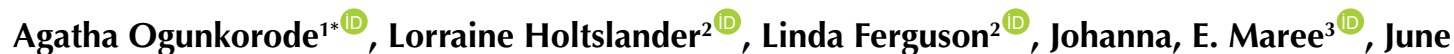 \\ Anonson $^{2}$, Vivian R. Ramsden ${ }^{4}$, Deborah, T. Esan ${ }^{1}$, Isaiah, D. Owoeye ${ }^{1}$
}

\begin{abstract}
Objectives: Globally, breast cancer is the commonest cancer in women. Empirical literature indicate that it is the second cause of cancerrelated mortality in high-resource regions, while it is the most common cause of cancer-related deaths among women in poor-resource regions. This study presents the suitability of the health belief model (HBM) as a framework for carrying out a comprehensive assessment of women with late-stage breast cancer in Nigeria.

Materials and Methods: This qualitative study employed interpretive description as its methodological approach, while the HBM was the conceptual framework. Two institutional review boards granted approval to conduct the study. Thirty women with advanced breast cancer were recruited for the study using purposeful sampling techniques. Components of the original HBM were identified to carry out the investigation. Data analysis was inductive.

Results: Findings indicated that the participants viewed breast cancer as a definite threat- both as a spiritual attack - an arrow shot by the enemy, and as a killer disease. Many of their perceptions appeared to be culturally based, while others were based on their individual experiences. They perceived some benefits to both traditional and medical treatment options.

Conclusions: Interventions that address people's cultural and individual perceptions enables a comprehensive assessment of the patients with breast cancer, which can improve the treatment outcomes and survival rates of disease.

Keywords: Late-stage breast ill-health, Breast cancer, Health belief model, Women, Southwestern Nigeria, Nigeria
\end{abstract}

\section{Introduction}

Breast cancer is the commonest malignancy diagnosed in women globally. It is the second cause of cancer-related death after lung cancer in high-resource, while it is the foremost cause of cancer-related deaths in poor-resource settings of the world $(1,2)$. Over 27000 new cases were diagnosed in 2012, accounting for 53\% of all other cancers in women, while 13960 deaths were recorded in Nigeria. This Figure amounted to $48.9 \%$ survival rate. Previous studies indicate that women in Nigeria typically report in the hospital with the advanced stages of the illnessdefined as stages III and IV, at which stage, cure is very difficult (1-3).

Despite the high mortality rates from cancer of the breast in Nigerian women, no empirical literature has been found that explored why women presented late for definitive breast cancer care in the hospital among this population. Also, there is no previous study that has explored the health-seeking behaviors of this population from the onset of the illness to the time they sought medical attention in the hospital.

In response to the paucity of data, this study was designed, using components of the HBM - perceived susceptibility, perceived seriousness, perceived benefits, perceived barriers, and cues to action - to identify problematic areas of delays in presenting at the hospital for medical care after becoming aware of breast ill-health. The authors in this paper present the suitability of the model as a framework for assessing women presenting with the advanced stages of breast cancer.

Identifying and addressing the problematic areas of delays may contribute to reducing the illness stage at diagnosis, which may significantly contribute to improving breast cancer treatment options and outcomes. Thus, improving the survival rate of the illness in the region.

\section{Materials and Methods \\ Study Setting}

The study was conducted in one of the foremost tertiary hospitals in Southwestern Nigeria. Southwestern Nigeria is on the Gulf of Guinea, very close to the bay. The northern and eastern boundaries of Southwestern Nigeria are formed by the Niger river. Much of the region is Savanah 
Key Messages

- A comprehensive and holistic assessment of breast cancer will inform adequate and effective management of the illness

- A holistic and comprehensive assessment includes the cultural perspective of the person involved

- Addressing culture-specific breast cancer-related issues might encourage early disease presentation that has the potential for improving the illness survival rate.

and tropical forests.

Southwestern Nigeria is made up of six states: Lagos, Oyo, Ogun, Ondo, Ekiti, and Osun, all of which were the focus of this study. Lagos state occupies an area of 3577 $\mathrm{km}^{2}$, with a population of 9113605 . Ogun state occupies an area of $16980.55 \mathrm{~km}^{2}$, with a population of $3,751,140$. Oyo state occupies an area of $28454 \mathrm{~km}^{2}$, with a population of $5,580,894$. Ondo state occupies an area of $15500 \mathrm{~km}^{2}$, with a population of 3460877 . Ekiti state occupies an area of $6353 \mathrm{~km}^{2}$, with a population of 2398957 . While Osun state occupies an area of $9251 \mathrm{~km}^{2}$, with a population of 3416959. The people live in the major cities and villages Google search, 2018.

The Southwestern region of Nigeria is majorly a Yorubaspeaking region. However, there are different Yoruba dialects among the people of the region. Ibadan, the city where the data collection took place, is the largest city in west Africa and the capital of Oyo-State. Due to the role of this city as the capital city, individuals from various ethnic groups and religions live there. All the regions of Southwestern Nigeria have common climate and weather conditions throughout the year. Southwestern Nigeria has periods of rain in the raining season from March to November and experiences dry season from November to February. (Retrieved from: https://www.naija.ng/1117167south-west-states-nigeria.html\#1117167)

The data was collected in a large urban-based universityaffiliated tertiary hospital. The hospital was chosen because of the diversity of the patient population that visit the hospital. The hospital is one of the best-equipped hospitals in Nigeria, and a treatment center where patients receive top-quality, comprehensive medical assessment, treatment, and care. The hospital is the oldest tertiary hospital in southwest region and it is a referral center. The oncology unit operates a daily outpatient clinic where patients with different stages of breast cancer are seen, assessed, and have their breast cancer treatment initiated. These patients in this unit are receiving varied treatments ranging from surgical intervention to chemotherapy and radiotherapy for the management of the disease. This oncology section was the recruitment outlet for the study.

\section{Study Design}

The study was a qualitative study. The methodological approach was interpretive description. Interpretive description (ID) engages a flexible and creative approach in generating knowledge to inform clinical understanding $(4,5)$. The framework of ID is based on the reasoning and logic applied at each decision-making point in the research process $(4,6)$. Interpretive Description is wellsuited for exploring how people give meaning to their lived experiences. It is an inductive analytic approach that acknowledges both the constructed and contextual nature of human experiences (6). Through ID, researchers identify patterns and themes in human experiences.

\section{Study Participants}

Thirty women with late-stage cancer of the breast defined as illness stages III or IV were purposively selected as study participants. They were all having symptoms and undergoing different treatment options for the disease. The participants were knowledgeable about breast cancer and they had characteristics that could help the researcher to achieve the aim and purpose of the study (7). The researcher established rapport with the participants before the commencement of the study to gain and ensure their trust and confidence, so to obtain quality data.

\section{Sampling and Sample Size}

As noted above, the purposeful sampling technique was used to choose participants with characteristics that could best contribute to the objectives of this study. The rationale and robustness of purposeful sampling lay in securing participants who possessed knowledge of, and experienced with the phenomenon under investigation (7). All the participants selected for this study were women referred from other hospitals for professional and specialist management of their advanced breast cancer and were willing to share their rich knowledge. The participants' shared mastery led to a deeper understanding of the women's health-seeking activities and the identification of the problematic areas of the delay, that is, the issues of key importance in this study.

\section{Inclusion and Exclusion Criteria}

The inclusion and exclusion criteria that guided the selection of participants for this study included (a) female gender; (b) diagnosis with stage III or stage IV breast cancer; (c) ability to communicate in either English or the Yoruba language or both; (d) ability to take part in an interview; (e) participation approved by the oncologist and contact or gate-keeper nurses; (h) inpatient at the hospital. The exclusion criteria included: (a) women with the diagnosis of stage III or stage IV breast cancer, which impeded the women's ability to participate in an interview; (b) those with advanced stage breast cancer who find it difficult to communicate; (c) an inability to communicate in either English or the Yoruba language. Data saturation was used to determine the appropriate sample size in this study. Data saturation, also referred to as data redundancy (4-7), occurs when the data collected 
has obtained adequate depth and richness. Researchers determine the point at which data saturation has occurred by being attuned to the number of times they hear the same information from a number of participants $(4,5,7,8)$. When they can anticipate that they will hear this same information from other participants, data saturation has been reached. At this point, the researchers are confident that no new differences on the emerging theory would likely appear from additional data collection (5-8).

\section{Data Collection}

The data collection was undertaken in two phases. The first phase consisted of participants completing a personal demographic information form, while the second phase consisted of participation in one-on-one, semistructured, and audio-recorded interviews guided by open-ended questions, and carried out by the researcher (AO). Broad topics on the interview guide included the participants' interpretation of their breast changes and their health-seeking behaviors after they noticed a breast abnormality (e.g., tell me in detail the interpretations of your illness signs and symptoms?), the nature of the symptoms, people or services centers contacted for advice, and the understanding that informed their healthseeking behaviors. Probes were used to get more in-depth information (e.g., can you explain more about this? can you give examples to make you better understood?). Each interview lasted for about 45-60 minutes. After the interviews, a summary of the points discussed were shared. Clarification and validation of collected date were done by the participants. They were asked to ask any questions and to speak more if they wanted to. The interview guide was pilot-tested before using it to collect the data. The same criteria used to select prospective participants for the larger study were used for the selection of the participants who took part in the pilot study. All data collection occurred in a private room in the hospital. Only the researcher (AO) and the participant being interviewed were present during the interview sessions.

\section{Data Analysis}

The participants' demographic questionnaires were analyzed using descriptive statistics, and transcripts from the interview were analyzed inductively by following the thematic analysis pathway propounded by Clarke and Braun (9). Data analysis began from the time of the first interview. The recorded interviews were transcribed verbatim by one researcher $(\mathrm{AO})$ as soon as the recording was conducted. All authors reviewed and matched the transcribed scripts with the recordings to ensure the accuracy of the data. All necessary corrections were made. Field notes were written. Reflective journaling was done. Identifiable information was removed to ensure participants' anonymity. Four researchers (AO, LH, LF and JA) read and re-read the transcripts again to ensure accuracy. Data were coded, managed and analyzed using NVivo version 10 (QSR International; Melbourne, Australia). Each transcript and notes were coded independently by all authors. Areas of discrepancies were resolved in consultation with experts during meetings. The first cycle coding identified broad-based codes, which was reviewed and revised by four study authors $(\mathrm{AO}, \mathrm{LH}$, LF, JA). All team members performed serial review of the coded interview data, focusing on similarities and differences. During the second phase coding conducted by all authors, similar codes were grouped into categories $(5,8)$.

\section{Methodological Rigor}

Four criteria including credibility, dependability, confirmability, and transferability were employed in ensuring the trustworthiness of this study findings $(10,11)$. In this study, credibility was ensured by (a) summarizing the participants' discussions during and at the end of the interviews, (b) consultation and discussions among the research team, and (c) maintaining an audit trail of the decisions made during the research process, and conducting a repeat interview with participants. Transferability was ensured by providing "thick descriptions" of the research process from the beginning to the end $(10,11)$. Dependability was ensured through consultation and meetings with experts throughout the research process. Member checking which involved sharing the initial tentative synthesis and interpretations based on the data collected with the study participants through telephone interviews confirmed the researcher's understanding of participant's shared experiences and minimized the researcher's personal biases. Confirmability was ensured through validation of the initial findings with the participants, personally transcribing the interviews, using participants' exact quotes, and maintaining a reflective journal to express the researcher's own biases and personal thoughts.

\section{Breast Cancer Staging and Classification}

The American Joint Committee on Cancer (AJCC) has described the extent of illness progression in cancer patients and classified breast cancer into four stages. The committee used the tumor size, the lymph node involvement, and metastases or the spread of the disease (TNM) as the basis for the classification. Stage I breast cancer was described as the initial stage of the disease. At this stage, the size of the tumor is small, and the tumor is contained within the organ where it started. At this stage, the illness is curable most of the time (12). Stage II breast cancer is counted as part of the early stages. The tumor size is bigger compared to stage I breast cancer. The lymph nodes closer to the affected breast are affected, but the tumor is still treatable, and the prognosis is good (12). In stage III breast cancer, the tumor has spread significantly to the surrounding lymph nodes and the surrounding tissues. In stage IV breast cancer, the tumor has spread to 
other organs and parts of the body.

Only five to $12 \%$ of stages I and II breast cancer patients die in the first decade after diagnosis, while over $60 \%$ of stage III, and over $90 \%$ of stage IV breast cancer patients die in the first ten years after diagnosis (12). Knowing the stages of breast cancer is useful because it enables the healthcare provider to estimate the prognosis for the illness. This knowledge can also provide valuable information about the most appropriate treatment options available to patients who present with breast cancer.

It must be pointed out that breast cancer is not a uniform illness, and many subtypes have been identified. Breast cancer subtypes vary across various populations and racial groups. One of the ways of defining the different categories of breast cancer is by using the hormone receptor status. The identification of the characteristics of the various categories is essential for the development and the provision of the most appropriate care strategies for the patients (13).

\section{Results}

Study Participants' Demographic Information

The demographic information of the study participants is presented in Table 1. The analyses of the participants' demographic information indicated that they had a varied level of education, employment, and economic status. Their age range was 29-68 years. Most of the participants were between 40 - and 50 years, with a mean of 47 years.

Table 1. Demographic Profile of Study Participants

\begin{tabular}{|c|c|c|}
\hline Item & Variables & No. $\%$ \\
\hline \multirow{4}{*}{ Tribe } & - Yoruba & $26(87)$ \\
\hline & - lbo & $1(3)$ \\
\hline & - Efic & $1(3)$ \\
\hline & - Edo & $2(6)$ \\
\hline \multirow{4}{*}{$\begin{array}{l}\text { Participants' } \\
\text { language }\end{array}$} & - Yoruba & $26(87)$ \\
\hline & - Ibo & $1(3)$ \\
\hline & - Efic & $1(3)$ \\
\hline & - Edo & $2(6)$ \\
\hline $\begin{array}{l}\text { Specific other } \\
\text { language }\end{array}$ & - English & $13(43)$ \\
\hline \multirow{2}{*}{$\begin{array}{l}\text { Religious } \\
\text { affiliation }\end{array}$} & - Christian & $24(80)$ \\
\hline & - Muslim & $6(20)$ \\
\hline \multirow{5}{*}{ Age group } & - $20-30$ & $1(3)$ \\
\hline & - $31-40$ & $4(13)$ \\
\hline & - $41-50$ & $17(57)$ \\
\hline & - $51-60$ & $4(13)$ \\
\hline & - $60+$ & $4(13)$ \\
\hline \multirow{5}{*}{$\begin{array}{l}\text { Educational } \\
\text { level }\end{array}$} & - Graduate degree e.g., Masters, PhD & $3(10)$ \\
\hline & - Bachelor's degree & $6(20)$ \\
\hline & $\begin{array}{l}\text { - Some college, associate degree, } \\
\text {-technical certificate }\end{array}$ & $11(36)$ \\
\hline & - Secondary school & $10(33)$ \\
\hline & - Less than primary 6 & $0(0)$ \\
\hline \multirow{2}{*}{$\begin{array}{l}\text { Familial history } \\
\text { of the disease }\end{array}$} & - Yes & $7(23)$ \\
\hline & - No & $23(77)$ \\
\hline
\end{tabular}

Findings From Interview Transcripts

Themes emerging from the thematic analysis of the participants' interview transcripts were cloistered into six themes: (1) breast cancer, a death sentence; (2) breast cancer, an arrow or an affliction from the enemy; (3) breast cancer provokes fear; (4) the wish to survive motivates breast cancer health-seeking; (5) breast cancer provokes stigmatization; (6) breast cancer spurs social support. These themes were supported by subthemes.

Theme 1. "Breast Cancer, a Death Sentence". "It is a death sentence." (a 40-year-old participant). This perception was expressed by another 60-year-old participant when she said: "whether you treat it or not, you will die." This theme relates to perceived seriousness. Perceived seriousness concerns a person's belief in the severity of an illness. All the participants in the study were aware of having contracted an illness that kills whomsoever is afflicted by it, resulting in their increased level of perceived threat.

Theme 2. "Breast Cancer, an Arrow, or an Affliction From the Enemy"

"It is a spiritual attack that is an arrow shot by the enemy" (42-year-old participant). Another participant corroborated this statement by saying: "To me, it is a spiritual attack. (61-year-old participant)". When asked to describe the methods used to manage her breast changes, a 33-year-old participant responded "I went to the traditional healer, the herbalist...I thought it was a kind of war from my enemy". This theme relates to cultural understanding of cancer of the breast as a spiritual attack. It also relates to the cultural perception of breast cancer as having a preternatural and supernatural origin. In the current study, advanced breast cancer was considered severe because it reflects attack from an adversary and hostility that can lead to fear, anxiety, and lack of trust in the community. The awareness of having contracted such an illness also heightened levels of threat, triggering participants' decision-making processes about involvement in health-seeking activities.

\section{Theme 3. Breast Cancer Provokes Fear}

"When they told me, I was afraid" (a 41-year-old participant); Another 40-year-old participant asked: "who can be given a death sentence and will not be afraid?" This theme also relates to perceived seriousness, because of the cultural perceptions of breast cancer as a spiritual attack and the personal perception of breast cancer as a killer disease.

In the current study, the advanced stages of breast cancer are considered to be severe because of the complications that accompany them. The awareness of the health and social implications of the advanced stages of breast cancer such as loss of a body part as in the cases of mastectomy, fear of stigma, potential effects of the illness 
on family life and marital relationships, complications of treatments, and fear of death might have resulted in a high level of emotional response heightening their perception of seriousness, their threat level, and prompting health seeking decision making and activities.

\section{Theme 4. The Wish to Survive Motivates Breast Cancer} Health-Seeking

"I have to endure because of my children. I want to live long" (A 45-year-old participant). When asked why she came to the hospital for care, a 44-year-old participant replied: "ha! I want solution to my breast ill-health; I don't want to die now". This theme relates to perceived benefits construct of the HBM. For an individual to engage in an action for managing health-related issues, the perceived benefits of the action must be judged to be higher than the perceived barriers. In our study, the desire to survive and live was judged by the participants to outweigh any barrier. This wish motivated some study participants to seek medical care in managing their breast changes.

\section{Theme 5. Breast Cancer Provokes Stigmatization}

"The major difficulty is stigmatization and all other jests that people will make of you." (A 44-year-old participant). This theme relates to perceived barriers construct of the HBM. In the current study, the identified barriers were as follows: stigma, the financial difficulties of breast cancer treatment, the effects of the illness on participants' social and marital relations, and the unpleasant side effects of breast cancer management such as dryness of the skin, and fear of body mutilation as in the cases of mastectomy. The participants in the current study did not perceive these barriers as outweighing the benefits of breast cancer treatments.

\section{Theme 6. Breast Cancer Spurs Social Support}

"With the help of the church, family, and friends, I did the operation." (a 60 -year-old participant). This idea was corroborated by a 32 -year-old participant when she was asked to talk more about her social support. She said "my friends were visiting me. They brough me gifts.... they counselled me". This theme relates to cues to action construct of the HBM. The participants in the current study found encouragement and support to engage in health-seeking behaviors in the influence and roles played by their family members, friends, church affiliations, and other social networks systems, which could be regarded as external cues to action and influence of psychosocial variables components of the HBM for these participants.

\section{Discussion}

\section{Constructs of the HBM}

This section presents the ways in which the constructs of the model predicted the health-seeking behavior of women presenting with advanced metastatic breast cancer, starting from the first time the women noticed breast changes to their engagement in definitive treatments for breast cancer in the hospital. The HBM addresses an individual's perception of the warning and the danger of a health issue and appraises health-seeking behavior in preventing or managing the health problem (14-17). Below is a discussion of the five concepts of HBM - perceived susceptibility, perceived severity, perceived barriers, perceived benefits, and cues to action $(14,16,17)$ and how they were used in our study.

\section{Health Belief Model}

The Health Belief Model (HBM) is a social-psychological model developed by Rosenstock (14) to explore why individuals fail to participate in relatively free health preventive services. Although there are several other health-related behavioral models, none approaches HBM regarding research attention (18). Notwithstanding its wide use for almost four decades, the major components of the model have remained unchanged. The HBM specifies several variables that seem to contribute to an understanding of health-seeking behaviors.

The Philosophical Underpinnings of the Health Belief Model The philosophical underpinnings of HBM involve motivating factors and the perceptions of the individual involved $(14,17)$. Rosenstock identified the HBM as a value-expectancy theory, which views behavior as dependent on the value placed on the possibility that a specific health-related action will result in a desired outcome. In the HBM, subjective beliefs are regarded as motivators for undertaking a health-related action $(14,17)$.

\section{The Assumptions of the Health Belief Model}

The assumptions of the HBM indicate that: (1) individuals take actions related to their health if they are convinced they are at risk for contracting an illness and if the action can either remove the illness or reduced its impact on some aspects of their lives; (2) they are likely to accept, take, and maintain the action if they see benefits in the specific health-related behavior and conversely, not to accept, take, and maintain the action if they see no benefits; (3) individuals take health-related action provided that its positive aspects outweigh the negative and they are confident in their skills and resources to undertake the health-related behavior $(14,17)$.

\section{Constructs of the Health Belief Model}

Perceived Susceptibility. Perceived susceptibility relates to a person's belief in the risk of contracting an illness $(14,17,19)$. Women presenting with the advanced stages of breast cancer are susceptible, otherwise they would not have contracted the illness. Findings from this study suggested that the risk for contracting the illness in women already diagnosed with late-stage breast cancer was no longer a concern. All the participants in the current study were aware of having contracted a severe illness, resulting 
in their heightened level of perceived threat.

Perceived Seriousness. Perceived seriousness concerns an individual's belief in the severity of a disease or health abnormality. The perceived degree of seriousness may be influenced by the strength of the psychological arousal created by the illness when one thinks about it and the perception of the kinds of difficulties a person believes a given illness will cause for her or him $(14,17,19)$. For all the participants in the current study, advanced breast cancer was considered severe because of the cultural perceptions of breast cancer as a spiritual attack and the personal understanding of cancer of the breast as a killer ailment. In addition, some manifestations of breast cancer, including painful and embarrassing breast changes aroused emotions related to the perceived psychological and physical consequences of the illness.

Perceived Benefits. Perceived benefits relate to a person's judgment of the worth of a health-seeking behavior. It concerns how beneficial the ill person judges the behavior to be $(14,17,19)$. Perceived benefits must be higher than the perceived barriers for a woman to adopt a remedial action for preventing the complications of the advanced stage of breast cancer. In the current study, the desire to survive and live was judged by the study participants, at least in the advanced stage of their illness, to be more beneficial than any barriers. This finding is consistent with the notions of the original HBM.

Perceived Barriers. Perceived barriers relate to the adverse aspects of a health-seeking action. It concerns the extent to which the action is inconvenient, expensive, painful, unpleasant, and upsetting $(14,17,19)$. They may be emotional, psychological, and material in nature. Barriers related to breast cancer health-seeking action may include access to care, financial implications of breast cancer care, effects on social relations, support system, effects on family life, and occupation. It is only if the woman perceives these barriers not to be stronger than the benefits of the health-seeking behaviors that such health-seeking actions will be accepted.

In the present study, the desire to survive was judged by the study participants to be more beneficial than any barriers, including stigma, and other unwarranted side effects of treatment. This finding is consistent with findings from a mixed method study conducted by Aduayi et al (20) to explore whether women in some rural and urban communities in Southwestern Nigeria would accept preventive bilateral mastectomy. The study findings indicated that the decision to remove both breasts through preventive bilateral mastectomy among high-risk individuals transcended social and spiritual boundaries. The findings from Aduayi et al (20) and those of the current study are consistent with the notions of the original HBM.

Cues to Action. Cues to action are either internal or external occurrences that can set in motion a decisionmaking process about the appropriate health-seeking action. Internal cues to action may include the signs and symptoms of illness, while external cues to action may include media communications, social interactions, and the influence of significant others $(14,17,19)$. If cues to action are forceful and intense, they may convince a woman who does not recognize the advanced stage breast cancer to be severe, to adopt a curative healthseeking behavior notwithstanding her initial impression and belief $(14,17,19)$. Religious leaders, community leaders, social network members and family members could offer encouragement, persuasion, and direct or indirect support for the desired behaviors (21). In line with Rosenstock $(17,19)$, the participants in the current study found encouragement and support to participate in health-seeking behaviors in the influence and roles played by their family members, friends, church affiliations, and other social networks systems, which could be regarded as external cues to action for these participants. These findings are consistent with the notions of the original HBM.

The Concept of Perceived Threat. This construct is a combination of perceived susceptibility and perceived seriousness. An increased level of threat can trigger a decision to seek healthcare. It can also motivate a person to accept, adopt, and maintain a health-related action $(14,17,19)$. The current study participants manifested signs of threat.

The perceived threat was likely influenced by any or a combination of the following factors: the individual's perception of breast cancer as a killer disease, and the cultural perception of breast cancer as a spiritual attack, as well as, some manifestations of breast cancer, including painful and embarrassing breast changes, which could be regarded as internal cues to action, aroused emotions related to the perceived psychological and physical consequences of the illness. The awareness of having contracted such an illness also heightened levels of threat, triggering participants' decision-making processes about engaging in health-seeking behaviors. Also, strategic reminders such as the supportive role of family members, friends, church members, in turn, influenced the participants' health-seeking behaviors. As observed in the study, a woman's perception of threat alone was enough to predict her likelihood of engaging in specific health-seeking behavior. Perceived benefits and perceived barriers also could predict behavior. The findings are consistent with the notions of the original HBM.

Cultural perception was not part of the original HBM. However, finding from this study suggests that initial consultation of some participants with traditional healers had contributed to delays in presentation in the hospital for the medical management of their illness. Sixty-four percent of these participants had consulted with the alternative care provider before coming to the hospital for medical attention. This finding is similar to finding from Ibrahim and Oludara (22) on factors associated with late 
presentation of breast cancer among Nigerian women. Their study findings indicated that $61.6 \%$ of their study participants engaged in alternative, spiritual and herbal medicine to treat the disease before presenting in the hospital.

\section{Cultural Perception}

The cultural background of the Yoruba people who occupy southwestern Nigeria influences their views of an illness and the health-seeking remedies employed in managing the illness. The Yoruba people believe that illness does not occur by chance. Therefore, a Yoruba person will explore why she or he becomes ill by consulting the traditional healer (23) who will consult the Ifa Oracle - "an ancient secret knowledge system". The traditional healer will also prescribe the necessary remedies for the illness (23). In the Yoruba culture, it is believed that illnesses have three origins: preternatural, natural, and supernatural (24). The preternatural origin relates to the magical practices of witches, sorcerers, and curses. Illnesses resulting from the infringement of social values like stealing are said to have natural origins. The supernatural cause of illness is attributed to the wrath of God and ancestors. The Yorubas also believe that some illnesses such as those originating from preternatural and supernatural origins can only be managed through their traditional healing methods, which are usually carried out by the native doctor, elders in the community, the herbalist, or the spiritualists (25-28).

Therefore, the perception of individuals about the cause of their illness will trigger a decision-making process to choose a health-seeking behavior that the individual perceives will be the most effective method from the available health-seeking options. If individuals believe that their illness has a supernatural or preternatural origin, they are more likely to seek health by engaging the services of a traditional or native healer. Thus, cultural perception plays an essential part in appraising the seriousness of an illness such as breast cancer, as well as the health-seeking decision-making process. It is, therefore, proposed that cultural perception be incorporated into the constructs of the model. Figure 1 presents a summary of the findings.

As depicted in Figure 1, perceived threat may be influenced by any one factor or a combination of modifying factors such as, sociocultural perception and experiences, and social and peer networks. These, in turn, may influence the likelihood of engaging in healthseeking action. Also, cues to action, which are regarded as triggers and strategic reminders, may activate the level of threat and encourage a woman to engage in health-seeking behavior. Cues to action can be sources of support and encouragement to adopting a health-seeking behavior.

A woman's perception of a threat resulting from having contracted a serious illness alone may predict her likelihood of engaging in health seeking behavior. A similar characteristic is also observed for the perceived benefit and perceived barriers. Also, perceived barriers and cues to action can be influenced by modifying factors. All these variables are interconnected, and they

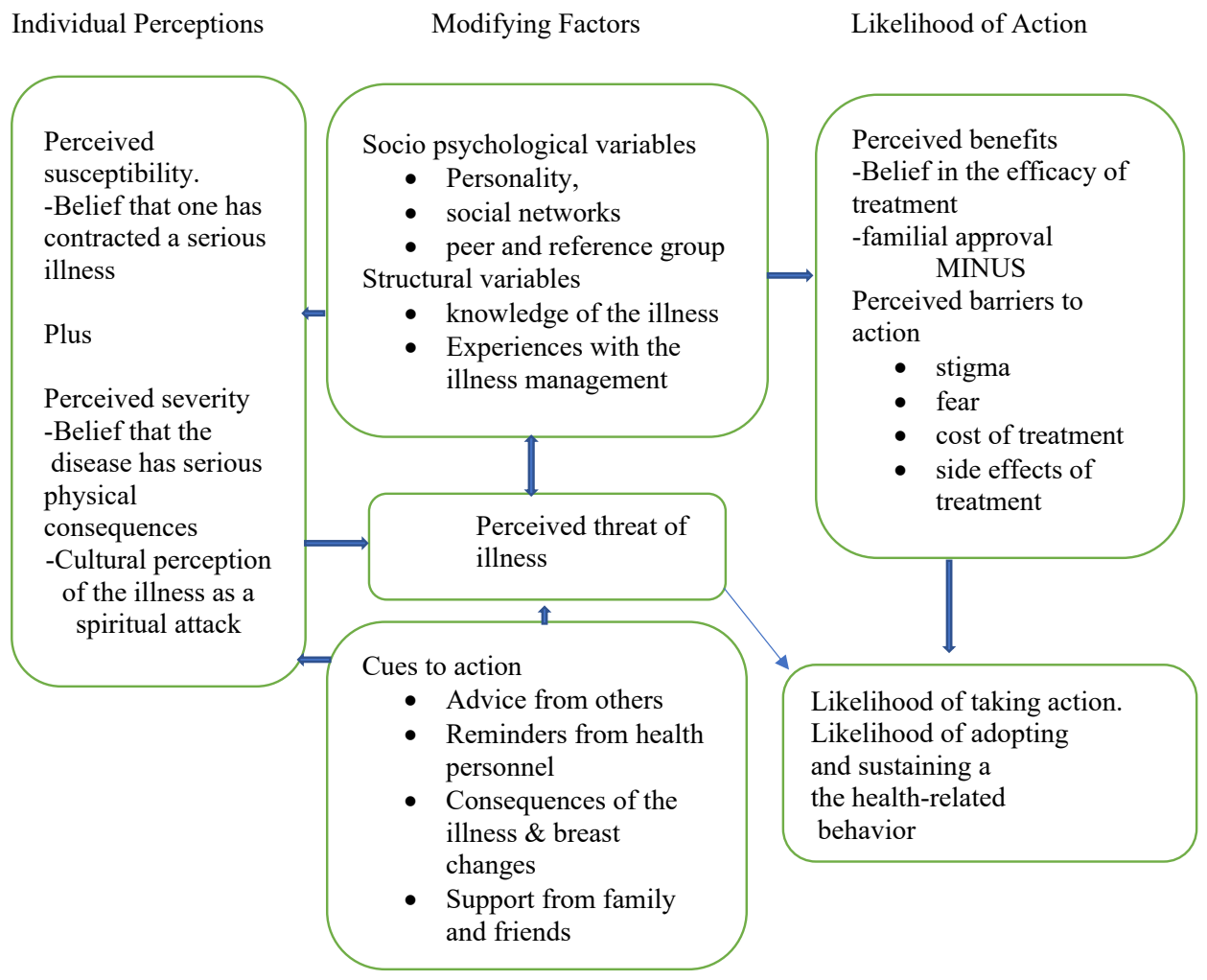

Figure 1. The Health Belief Model. Source: The Health Belief Model (Adapted From Rosenstock (17)). 
have impact on the likelihood of engaging in a healthseeking behavior. However, to carry out a comprehensive and holistic assessment of women with late-stage cancer of the breast, it is essential to understand the patient's cultural perspective and take this into consideration in the planning and implementation of care.

\section{Implications for Practice}

Nurses, other healthcare providers, and breast cancer stakeholders are in ideal positions to identify and counter perceived barriers and problematic areas of delay preventing early presentation of breast cancer for medical care. For example, the care provider can plan and implement programs and strategies that acknowledge and address the personal, cultural, and community factors that influence the perceptions of breast cancer and its management. Findings from the study also indicated the need to addressing culture-specific breast cancer-related issues. Nurses, other healthcare providers, and other breast cancer stakeholders can provide a comprehensive community-based breast health education. The understanding emerging from this study can inform the addition of specific information about breast ill-health, the importance of early detection and treatment options during health promotion programs. The outcomes from this study can equip breast cancer caregivers to provide culturally sensitive services and contextually relevant interventions.

\section{Study Limitations}

Some limitations have been identified. First, since the study was conducted in Southwestern Nigeria, which is densely populated by the Yoruba ethnic group, the views of this study population which is predominantly Yourba ethnic group may not necessarily reflect the understanding of women from other geopolitical zones in Nigeria. Therefore, a caution might be needed in generalizing the study findings to other ethnic groups in Nigeria. Interpretive description acknowledges that phenomena are neither time nor context-free. Generalization is not the aim; the goal is knowledge development. However, the in-depth knowledge gained through this study can benefit healthcare delivery. Furthermore, knowledge transferability may be possible depending on the degree of similarities in setting and circumstances (29). Second, the interviews were audio-recorded, which could have affected the quality of the data gathered because the participants' awareness of the audio-recorder might have affected how they shared their experiences.

\section{Conclusions}

In this paper, the suitability of the HBM as an assessment framework for women with late-stage cancer of the breast, that is, stage III or IV metastatic breast cancer in southwestern Nigeria has been discussed. Finding from this study suggest that initial consultation of some participants with the traditional healers contributed to delays in presentation for medical management in the hospital. Individual perceptions, cultural perceptions, and breast cancer symptom interpretations and experiences all influenced participants' choice of health-seeking activities. The supportive roles of family members, including friends, and social allies reduced the degree of participant's psychological reactions to their perceived barriers. However, to adequately assess and holistically manage breast cancer, a comprehensive assessment needs to be carried out. A comprehensive and holistic assessment need to include the cultural perception of the patient. There is the need for a comprehensive evidence-based community education on the etiology, signs and symptoms and treatment options for women with breast ill-health. It is, therefore, proposed that a cultural perspective be incorporated into the constructs of the HBM.

\section{Authors' Contribution}

$\mathrm{AO}, \mathrm{LH}, \mathrm{LF}, \mathrm{JM}$ and JA designed the study. AO, LH, LF developed the interview guides. $\mathrm{AO}$ conducted the interviews. All authors ( $\mathrm{AO}, \mathrm{LH}, \mathrm{LR}$, JA, JM, VR, DTE, IDO) coded the transcripts, analyzed the data, revised it critically for important intellectual content, and approved the final manuscript.

\section{Conflict of Interests}

Authors declare that they have no conflict of interests.

\section{Ethical Issues}

The researcher's University Behavioral Research Ethics Board (REB) granted ethical approval (REB \#18-03) to conduct the study. Operational approval (UI/EC/18/007) was given by the authorities of the health institution where the study took place. Efforts were made to ensure the participants' rights as study participants were protected. All participants were informed that their participation in the study was voluntary and they were aware of their rights to withdraw from the study at any time if they wished to do so without any penalty. Written informed consent was obtained from all prospective study participants, following informed consent procedures, before participation in the study. Every attempt was made to ensure the study participants' anonymity and confidentiality of the information provided.

\section{Data Availability}

The data analyzed and presented in this study are available upon request from the corresponding author.

\section{Financial Support}

This research did not receive any specific grant from funding agencies in the public, commercial, or non-for-profit sectors.

\section{Acknowledgments}

The authors' appreciation goes to all the breast cancer patients who participated in this study.

\section{References}

1. WHO. GLOBOCAN 2012. Cancer fact sheets breast cancer. 2017.

2. Ferlay J, Soerjomataram I, Dikshit R, et al. Cancer incidence and mortality worldwide: sources, methods and major patterns in GLOBOCAN 2012. Int J Cancer. 2015;136(5): E359-86. doi:10.1002/ijc.29210

3. Jedy-Agba E. Breast cancer in sub-Sahara Africa: Determinants of stage at diagnosis and diagnostic delays in women with symptomatic breast cancer. London: London School of Hygiene and Tropical Medicine; 2017.

4. Thorne S, Stephens J, Truant T. Building qualitative study 
design using nursing's disciplinary epistemology. J Adv Nurs. 2016;72(2):451-60. doi:10.1111/jan.12822

5. Thorne S. Interpretive description: Qualitative research for applied practice. 2nd ed. Morse J, editor. New York: Routledge, Taylor \& Francis; 2016. doi:10.4324/9781315545196

6. Thorne S, Kirkham SR, MacDonald-Emes J. Interpretive Description: A noncategorical qualitative alternative for developing nursing knowledge. Res Nurs Health. 1997;20(2):169-77. doi:10.1002/ (SICI)1098-240X(199704)20:2<169::AID-NUR9>3.0.CO;2-I

7. Patton MQ. Qualitative Research \& Evaluation Methods: Integrating Theory and Practice. SAGE Publications; 2014.

8. Thorne S, kirkham SR, O'Flynn-Magee K. The analytic challenge in Interpretive Description. International Journal of Qualitative Methods. 2004;3(1):11. doi:10.1177/160940690400300101

9. Clarke V, Braun V. Teaching thematic analysis: Overcoming challenges and developing strategies for effective learning. Psychologist. 2013;26(2):120-3.

10. Morse JM. Critical Analysis of Strategies for Determining Rigor in Qualitative Inquiry. Qualitative Health Research. 2015;25(9):121222. doi:10.1177/1049732315588501

11. Lincoln YS, Guba EG. Naturalistic inquiry. Newbury, CA: Sage; 1985. doi:10.1016/0147-1767(85)90062-8

12. Singletary SE, Connolly JL. Breast cancer staging: Working with the sixth edition of the AJCC cancer staging manual. CA Cancer J Clin. 2006;56(1):37-47. doi:10.3322/canjclin.56.1.37

13. Adisa CA, Eleweke N, Alfred AA, et al. Biology of breast cancer in Nigerian women: a pilot study. Ann Afr Med. 2012;11(3):169-75. doi:10.4103/1596-3519.96880

14. Rosenstock IM. The Health Belief Model and Preventive Health Behavior. Health Educ Monogr. 1974;2(4):354-86. doi:10.1177/109019817400200405

15. Carpenter CJ. A Meta-Analysis of the Effectiveness of Health Belief Model Variables in Predicting Behavior. Health Commun. 2010;25(8):661-doi:10.1080/10410236.2010.521906

16. Rosenstock IM. Historical origins of the health belief model. Health Education Monographs. 1974;2(4),328-335. doi.10.1177/109019817400200403.

17. Rosenstock IM. Why People Use Health Services. The Milbank Memorial Fund Quarterly. 1966;44(3):94-127. doi: $10.2307 / 3348967$
18. Janz NK, Becker MH. The health belief model: A decade later. Health Educ Q. 1984;11(1):1-47.doi:10.1177/109019818401100101

19. Hochbaum GM, Rosenstock I, Kegels S. Health belief model. Public Health Services, Tuberculosis program. Washington, DC: US Government Printing Office; 1952.

20. Aduayi V, Onayade A, Aduayi O, ljadunola M. Willingness to accept preventive bilateral mastectomy among women in rural and urban communities in South-Western Nigeria. Int J Community Med Public Health. 2015;2(2):86. doi:10.5455/23946040.ijcmph20150504

21. Aghdam MA, Sanaat Z, Hassankhani H, Kochaki Nejad Z. Self-efficacy in breast cancer patients: A systematic review. International Research Journal of Applied and Basic Sciences. 2013;4(5):1007-13.

22. Ibrahim NA, Oludara MA. Socio-demographic factors and reasons associated with delay in breast cancer presentation: a study in Nigerian women. Breast. 2012;21(3):416-8. doi:10.1016/j. breast.2012.02.006

23. Ogundele SO. Aspects of Indigenous Medicine in South Western Nigeria. Studies on Ethno-Medicine. 2007;1(2):127-33.doi:10.31 901/24566772.2007/01.02.02

24. Jegede A, S. The Yoruba cultural construction of health and illness. Nordic Journal of African Studies. 2002;11(3):322-35.

25. Adepoju JA. A study of the health beliefs and practices of the Yoruba. J Cult Divers. 2012;19(2):36-43.

26. Jegede RO, Odejide AO, Sijuwola AO. Rural Mental Health Care in Nigeria. Int J Ment Health. 1983;12(1-2):159-69. doi:10.1080/0 0207411.1983.11448943

27. Oladimeji KE, Tsoka-Gwegweni JM, Igbodekwe FC, et al Knowledge and Beliefs of Breast Self-Examination and Breast Cancer among Market Women in Ibadan, South West, Nigeria. PLoS One. 2015;10(11):e0140904. doi:10.1371/journal. pone.0140904

28. Oluwatosin OA, Oladepo O. Knowledge of breast cancer and its early detection measures among rural women in Akinyele Local Government Area, Ibadan, Nigeria. BMC Cancer. 2006;6:271. doi:10.1186/1471-2407-6-271

29. Creswell JW. Qualitative inquiry and research design: Choosing among five alternatives. 2nd ed. Thousand Oaks: Sage Publications; 2007:414.

(C) 2021 The Author(s); This is an open-access article distributed under the terms of the Creative Commons Attribution License (http:// creativecommons.org/licenses/by/4.0), which permits unrestricted use, distribution, and reproduction in any medium, provided the original work is properly cited. 